\title{
Seleksi Karyawan Baru Menggunakan Metode Composite Perfomence Index (CPI) dan Rank Order Centroid (ROC)
}

\author{
Miftahul Walid $^{1}$, Budi Satria ${ }^{2}$, Masdukil Makruf ${ }^{3}$ \\ ${ }^{1,3}$ Teknik Informatika, Universitas Islam Madura \\ ${ }^{2}$ Teknik Informatika, Amik Mitragama \\ miftahwalid@gmail.com
}

\begin{abstract}
Abstrak
Dalam meminimalisir kesalahan serta subyektifitas keputusan untuk seleksi karyawan baru diperlukan sebuah system pendukung keputusan (Decision Support System / DSS ) yang dapat membantu bagian SDM untuk memutuskan karyawan yang akan diterima atau tidak, dalam penelitian ini digunakan kombinasi metode Composite Perfomence Index (CPI) dan Rank Order Centroid (ROC) pada system pembobotannya, luaran dari penelitian ini adalah berupa nilai perengkingan, dimana dari empat alternatif yang dihitung, alternatif pertama yaitu A1 memiliki rengking tertinggi dengan nilai 145,25 dikuti oleh A2 dengan nilai 140,25, selanjutnya A4 dengan nilai 128,3 dan rengking terahir adalah A3 dengan nilai 126. Dapat disimpulkan bahwa metode Composite Perfomence Index (CPI) yang dikombinasikan dengan metode Rank Order Centroid (ROC) dalam system pembobotan setiap kriteria dapat melakukan perengkingan yang baik dan mampu meminimalisir subjektifitas dari sistem pembobotan secara manual.
\end{abstract}

Kata Kunci : DSS, CPI, ROC, Seleksi Karyawan baru

\begin{abstract}
In minimizing errors and decision subjectivity for the selection of new employees, a decision support system (Decision Support System / DSS) is needed that can help the HR department to decide which employees will be accepted or not, in this study used a combination of Composite Performance Index (CPI) and Rank Order Centroid (ROC) in the weighting system, the output of this study is in the form of a ranking value, the four alternatives calculated, the first alternative, namely $A 1$ has the highest ranking with a value of 145.25 , followed by $A 2$ with a value of 140.25, then A4 with a value of 128.3 and the last rank is A3 with a value of 126. It can be concluded that the Composite Performance Index (CPI) method combined with the Rank Order Centroid (ROC) method in the weighting system of each criterion can perform a good ranking and cab minimize the subjectivity of the weighting system as a whole Manually
\end{abstract} Keywords: DSS, CPI, ROC, New Employee Selection

\section{PENDAHULUAN}

Karyawan adalah salah satu faktor yang menjadi penentu keberhasilan sebuah perusahaan. Kualitas karyawan yang baik, akan mempermudah perusahaan dalam memanajemen segala aktivitas yang dilakukan, sehingga target yang telah ditetapkan dapat mudah untuk dicapai. Untuk mendapatkan karyawan yang berkualitas, perlu dilakukan beberapa tahapan, salah satunya dengan melakukan seleksi yang ketat dalam proses rekrutmen, Seleksi merupakan tahapan untuk menentukan apakah seorang calon karyawan dinyatakan diterima atau tidak. Dari keputusan yang diambil harus dilakukan secara transparan dan objektif. sehingga kualitas karyawan yang diperoleh sesuai harapan dan tidak ada pihak yang dirugikan. Penetapan 
pengambilan keputusan calon karyawan diterima atau tidak, didasarkan pada kriteria yang telah ditetapkan oleh perusahaan, misalnya interview dan tes tulis yang dilakukan.

Dalam meminamalisir kesalahan serta menjaga objektifitas dan tranparansi dalam mengambil keputusan diperlukan sistem yang mampu menjadi pendukung keputusan yang dapat membantu bagian sumber daya manusia (SDM) dalam melakukan seleksi karyawan untuk memutuskan calon karyawan mana yang akan diterima dan tidak diterima. sistem pendukung keputusan merupakan suatu sistem yang dibangun berdasarkan beberapa model untuk membantu menyelesaikan permasalahan semiterstruktur seperti dalam permasalahan dalam penelitian ini.

Penelitian ini dilakukan untuk membantu sebuah perusahaan dalam pengambilan keputusan pemilihan karyawan dengan menggunakan model Perengkingan, proses perengkingan dilakukan dengan membandingan nilai setiap kriteria pada setiap alternatif, selanjutnya dibentuklah sebuah matrik perbandingan berpasangan dan memberikan bobot pada setiap kriteria berdasarkan dari tingkat kepentingannya sehingga diperoleh suatu nilai output atau keluaran yang selanjutnya akan dijadikan sebagai dasar pengambilan keputusan.

Metode perengkingan yang digunakan dalam penelitian ini adalah metode Composite Perfomence Index (CPI), terdapat beberapa penelitian yang telah dilakukan dengan menggunakan metode CPI antara lain; Metode ini pernah digunakan untuk menentukan penerima program bedah rumah untuk keluarga miskin, xadapun permasalahan dalam penelitian tersebut adalah instansi yang ditugaskan mengalami kesulitas dalam melakukan seleksi penerima program bedah rumah [1], metode Composite Perfomence Index (CPI) juga pernah digunakan dalam pemilihan pengurus OSIS, dimana proses pemilihan yang hanya dengan menggunakan penilaian yang didasarkan pada analisa pribadi guru yang bertindak sebagai pembina atau dinilai secara subjektif, sehingga dimungkinkan keputusan yang diambil tidak objektif dan cenderung memihak. untuk menjaga objektivitas dalam pemilihan maka dibuatlah sebuah sistem pendukung keputusan yang dapat mambantu pembina dalam menentukan siapa siswa-siswi yang berhak manjadi pengurus dengan didasarkan pada beberapa kriteria, antara lain, kemampuan di bidang akademik, kedisiplinan dan komunikasi (kemampuan bicara) [2]. Penelitian lain dengan menggunakan metode yang sama juga dilakukan dalam pemilihan guru terbaik, Sistem yang dibuat dapat mempermudah dalam melakukan seleksi serta mempercepat proses seleksi karyawan. Dengan adanya sistem tersebut dapat mengurangi kesalahan dan pemilihan secara tidak objektif [3], Adelina dkk, pernah menggunakan metode CPI dalam seleksi penerimaan koki, keberhasilan usaha restoran tergantung pengelolahan didalamnya, salah satunya adalah dalam hal seleksi penerimaan koki yang kompeten. maka dalam mengatasi permasalahan dalam peneltian tersebut dibuatlah sebuah sistem pendukung keputusan yang berfungsi untuk melakukan seleksi kandidat koki yang sesuai dengan kriteria yang telah ditentukan [4]. 
Penelitian tentang seleksi atau rekrutmen karyawan telah banyak dilakukan salah satu metode yang pernah digunakan adalah Simple Addative Weighted (SAW) penelitian ini dilakukan oleh sundari dan taufik pada tahun 2014 [5], pada tahun 2017 Setianingsih telah menggunakan kombinasi dua metode yaitu metode Simple Addative Weighted (SAW) dan TOPSIS [6], Arifianto dan Irwansyah juga menggunakan metode Analitycal Hirarchy Process (AHP) dalam rekrutmen karyawan [7], maka dalam penelitian digunakan metode Composite Perfomence Index (CPI) untuk seleksi karyawan baru, dalam metode CPI membutuhkan pembobotan pada setiap kriteria yang digunakan, dalam penelitian ini digunakan metode Rank Order Centroid (ROC) [8][9][10], untuk menjaga objektifitas nilai bobot pada setiap kriteria yang digunakan, diharapkan dari penelitian ini dapat membantu bagaian sumber daya manusia (SDM) perusahaan dapat dipermudah dalam melakukan seleksi karyawan.

\section{LANDASAN TEORI}

Penelitian tentang Composite Perfomance Index (CPI) telah banya dilakukan antara lain digunakan untuk penentuan remunerasi karyawan, dimana dalam penelitian ini Metode CPI dibandingkan dengan metode Simple Additive Weighted (SAW), Dimana metode SAW lebih cepat sebesar 89-93\% dibandingkan dengan metode CPI. Oleh karena itu diharapkan aplikasi ini dapat menjadi bahan evaluasi untuk kebutuhan pelatihan dan pengembangan agar kinerja pegawai menjadi lebih optimal [13]. CPI juga pernah digunakan untuk membuat sistem pendukung keputusan untuk pemilihan hotel di lubuklinggau, dalam penelitian ini terdapat 7 data hotel yang akan dinilai, dari 7 data tersebut Hotel Dafam menjadi peringkat pertama dengan nilai 200, dan Hotel Hakmaz Taba Syariah dengan nilai 170, dan Hotel Burza dengan nilai 150 [11].

Metode Composite Performance Index (CPI) Merupakan salah satu metode dengan menggunakan indeks gabungan (Composite Index) untuk menentukan penilaian atau peringkat beberapa alternatif berdasarkan kriteria - kriteria yang ditentukan sebelumnya [11]. Adapun tahapan penyelesaian metode CPI, pertama melakukan identifikasi kriteria tren positif . dan tren negatif, tahap kedua pemberian nilai bobot berdasarkan nilai kepentingan setiap variabel, dimana dalam penelitian ini menggunakan metode ROC, tahap ke-tiga adalah normalisasi matrik dengan menggunakan persamaan (1) dan (2), pemilihan persamaan tergantung pada tren setiap kriteria, tahap ke-empat adalah mengalikan nilai kriteria setiap alternatif dengan nilai bobot setiap kriteria menggunakan persamaan (4), tahap terahir adalah menjumlahkan seluruh nilai kriteria setiap alternatif dengan menggunakan persamaan (5).

Adapun persamaan composite Perfomence Index (CPI) adalah sebagai beikut

$A_{i j}=\left(\frac{X_{i j}}{X_{i j}(\min )}\right) \times 100$, untuk tren positif.

$A_{i j}=\left(\frac{X_{i j}(\min )}{X_{i j}}\right) \times 100$, untuk tren negatif.

$$
A_{(i+1, j)}=\left(\frac{X_{(i+1, j)}}{X_{i j}(\min )}\right) x 100
$$

$I_{i j}=A_{i j} x P_{j}$ 


$$
I_{i}=\sum_{i=1}^{n} I_{i j}
$$

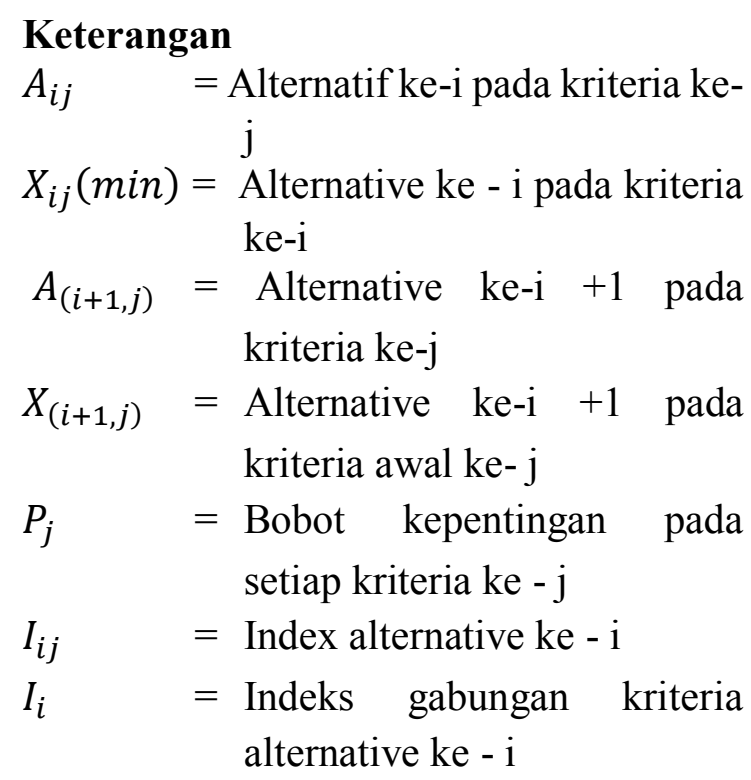

Untuk menjaga objektifitas sistem pembobotan pada setiap kriteria, digunakan metode Rank Order Centroid (ROC), sistem pembobotan dalam metode ROC, bahwa kriteria pertama dianggap lebih penting dari kriteria selanjutnya, adapun persamaannya adalah sebagai berikut;

$\mathrm{W}_{1}>\mathrm{W}_{2}>\mathrm{W}_{3} \ldots \mathrm{W}_{\mathrm{n}}$

Nilai bobot (W) dapat dihasilkan dengan rumus berikut :

$$
\begin{aligned}
& W_{j} \\
& =\frac{1}{n} \sum_{k}^{n}=j \frac{1}{k}
\end{aligned}
$$

sehingga ditulis

$\mathrm{W}=\left[\mathrm{w}_{1}, \mathrm{w}_{2} \ldots \mathrm{W}_{\mathrm{n}}\right]$

\section{METODE PENELITIAN}

Metode yang digunakan dalam penelitian ini adalah metode Kuantitatif, dimana penelitian dilakukan dengan menyuguhkan data dalam bentuk angka, kemudian data diolah dengan menggunakan sebuah metode sehingga menghasilkan sebuah nilai atau angka baru yang kemudian dijadikan sebuah konklusi, jawaban, keputusan atau jawaban dari penelitian yang dilakukan, penelitian ini juga merupakan penelitian pengembangan dari penelitian sebelumnya yang bertujuan mengembangkan sistem pendukung keputusan dalam melakukan seleksi calon karyawan baru menggunakan metode Composite Performance Index (CPI).

Dalam penelitian ini fokus untuk bagaimana melakukan seleksi karyawan baru yang nantinya akan diterima dengan model perengkingan, metode yang diusulkan adalah metode yang di dalamnya membutuhkan Pembobotan pada setiap kriteria dalam mengambil keputusan yaitu Metode CPI, tahapan penelitian ditunjukkan pada gambar 1. output yang diharapkan dari penelitian ini adalah sistem yang bisa melakukan seleksi dengan model perengkingan. 


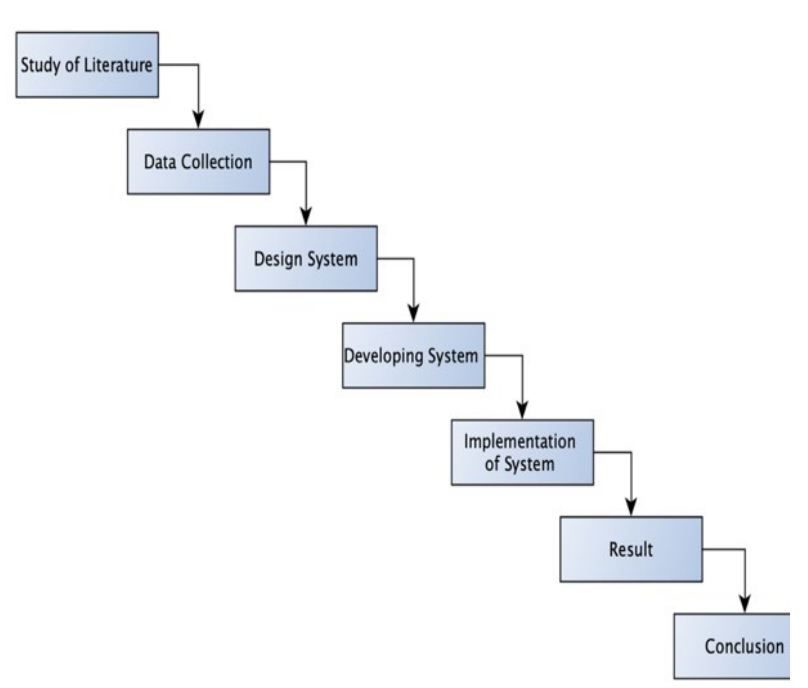

Gambar 1. Tahapan Penelitian

Adapun tahapan penelitian dalam penelitian ini antara lain, pertama adalah studi literatur, berfungsi untuk mencari refrensi baik berupa buku, jurnal dan literatur lainnya yang berhubungan dengan penelitian ini. Kedua adalah pengumpulan data, dilakukan untuk mengumpulkan data primer maupun sekunder yang dibutuhkan dalam penelitian ini seperti data - data kandidat karyawan baru dan hal - hal yang berhubungan dengan kriteria yang bisa menjadi variabel dalam menentukan karyawan berkualitas. Ketiga adalah perancangan sistem, dilakukan untuk menjelaskan tentang flowchart dan desain sistem yang akan dibuat dalam penelitian ini. Ke-empat adalah implementasi, dilakukan untuk menampilkan hasil penelitian yang telah dibuat. Ke-lima adalah validasi hasil, berfungsi untuk mengetahui output dari sistem yang dibuat apakah sudah sesuai dengan yang diharapkan atau masih perlu adanya evaluasi. Terahir adalah Penarikan kesimpulan dilakukan untuk memberikan penjelasan secara ringkas dan jelas dari hasil penelitian yang telah dilakukan.

\section{HASIL DAN PEMBAHASAN}

Dalam penelitian ini Composite Perfomence Index (CPI) membutuhkan beberapa kriteria yang telah ditentukan untuk mendapatkan alternatif terbaik untuk dijadikan karyawan, terdapat 7 kriteria yang digunakan antara lain; karakter, keahlian, kecakapan, penampilan, test tulis, usia dan wawancara [12]. Penjelasan tentang kriteria lebih detail dapat dilihat pada tabel 1 .

Tabel 1. Variabel Kriteria

\begin{tabular}{|c|c|c|}
\hline No & Kriteria & Keterangan \\
\hline 1 & $\mathrm{~K}_{1}$ & keahlian, \\
\hline 2 & $\mathrm{~K}_{2}$ & Kecakapan \\
\hline 3 & $\mathrm{~K}_{3}$ & Tes Tulis \\
\hline 4 & $\mathrm{~K}_{4}$ & Wawancara \\
\hline 5 & $\mathrm{~K}_{5}$ & karakter, \\
\hline 6 & $\mathrm{~K}_{6}$ & Peneampilan \\
\hline 7 & $\mathrm{~K}_{7}$ & Usia \\
\hline
\end{tabular}

Selain kriteria dalam proses perhitungan metode Composite Perfomence Index juga membutuhkan pembobotan $(W)$ pada setiap kriteria, hal ini dilakukan untuk membedakan antara kriteria yang memiliki nilai kepentingan yang lebih tinggi dibanding dengan kriteria yang lain. Untuk menjaga objektifitas dari pemberian bobot digunakan metode Rank Order Centroid (ROC) Penjelasan detail tentang bobot dalam dilihat pada tabel 2 .

Tabel 2. Bobot Setiap Kriteria

\begin{tabular}{|c|c|c|c|}
\hline No & Kriteria & Bobot (ROC) & Keterangan \\
\hline 1 & $\mathrm{~K}_{1}$ & keahlian, & keahlian, \\
\hline 2 & $\mathrm{~K}_{2}$ & Kecakapan & Kecakapan \\
\hline 3 & $\mathrm{~K}_{3}$ & Tes Tulis & Tes Tulis \\
\hline 4 & $\mathrm{~K}_{4}$ & Wawancara & Wawancara \\
\hline 5 & $\mathrm{~K}_{5}$ & karakter, & karakter, \\
\hline 6 & $\mathrm{~K}_{6}$ & Peneampilan & Penampilan \\
\hline 7 & $\mathrm{~K}_{7}$ & Usia & Usia \\
\hline
\end{tabular}

Sedangkan untuk pembobotan pada setiap variable kriteria akan ditampilkan tabel $3 \mathrm{~s} / \mathrm{d} 9$. 
Tabel 3. Variabel Keahlian

\begin{tabular}{|c|c|}
\hline Bobot & Keterangan \\
\hline 1 & Sangat buruk \\
\hline 2 & Buruk \\
\hline 3 & Cukup \\
\hline 4 & Baik \\
\hline 5 & Sangat Baik \\
\hline
\end{tabular}

Tabel 4. Variabel Kecakapan

\begin{tabular}{|c|c|}
\hline Bobot & Keterangan \\
\hline 1 & Sangat buruk \\
\hline 2 & Buruk \\
\hline 3 & Cukup \\
\hline 4 & Baik \\
\hline 5 & Sangat Baik \\
\hline
\end{tabular}

Tabel 5. Variabel Tes Tulis

\begin{tabular}{|c|c|}
\hline Bobot & Keterangan \\
\hline 1 & Test $<50$ \\
\hline 2 & $50<$ Test $<60$ \\
\hline 3 & $60<$ Test $<70$ \\
\hline 4 & $70<$ Test $<80$ \\
\hline 5 & $80<$ Test $<100$ \\
\hline
\end{tabular}

Tabel 6. Variabel Wawancara

\begin{tabular}{|c|c|}
\hline Bobot & Keterangan \\
\hline 1 & Sangat buruk \\
\hline 2 & Buruk \\
\hline 3 & Cukup \\
\hline 4 & Baik \\
\hline 5 & Sangat Baik \\
\hline
\end{tabular}

Tabel 7. Variabel Karakter

\begin{tabular}{|c|c|}
\hline Bobot & Keterangan \\
\hline 1 & Sangat buruk \\
\hline 2 & Buruk \\
\hline 3 & Cukup \\
\hline 4 & Baik \\
\hline 5 & Sangat Baik \\
\hline
\end{tabular}

Tabel 8. Variabel Penampilan

\begin{tabular}{|c|c|}
\hline Bobot & Keterangan \\
\hline 1 & Sangat buruk \\
\hline 2 & Buruk \\
\hline 3 & Cukup \\
\hline 4 & Baik \\
\hline 5 & Sangat Baik \\
\hline
\end{tabular}

Tabel 9. Variabel Usia

\begin{tabular}{|c|c|}
\hline Bobot & Keterangan \\
\hline 1 & $15>$ Usia $>30$ \\
\hline 2 & $15<$ Usia $<19$ \\
\hline 3 & $19<$ Usia $<23$ \\
\hline 4 & $23<$ Usia $<27$ \\
\hline
\end{tabular}

\begin{tabular}{|l|l|}
\hline 5 & $27<$ Usia $\leq 30$ \\
\hline
\end{tabular}

Nilai Tren pada setiap kriteria dijelaskan pada tabel 10.

Tabel 10. Nilai Tren Setiap Kriteria

\begin{tabular}{|c|c|c|}
\hline Kriteria & Keterangan & Tren \\
\hline $\mathrm{K}_{1}$ & Keahlian & + \\
\hline $\mathrm{K}_{2}$ & Kecakapan & + \\
\hline $\mathrm{K}_{3}$ & Test Tulis & + \\
\hline $\mathrm{K}_{4}$ & Wawancara & + \\
\hline $\mathrm{K}_{5}$ & Karakter & + \\
\hline $\mathrm{K}_{6}$ & Penampilan & + \\
\hline $\mathrm{K}_{7}$ & Usia & - \\
\hline
\end{tabular}

Berdasarkan langkah-langkah penyeleksian untuk menentukan seleksi karyawan baru dengan menggunakan metode Composite Perfomence Index (CPI), maka langkah yang harus dilakukan yaitu Memberikan nilai setiap alternatif ( $\mathrm{Ai}$ ) pada setiap kriteria ( $\mathrm{Cj}$ ) yang sudah ditentukan disajikan pada tabel 11, kemudian dilakukan normalisasi matrik dengan rumus $=(\mathrm{Cj}: \min \mathrm{Cj}) \times 100$ untuk kriteria dengan tren positif dan rumus $=$ (min $\mathrm{Cj}$ : $\mathrm{Cj}$ ) x 100 untuk kriteria dengan tren negatif disajikan pada table 12 , proses selanjutnya adalah mengalikan bobot dengan hasil normalisasi matrik yang sajikan pada Tabel 13, terahir dilakukan perengkingan dengan menjumlahkan seluruh nilai kriteria pada setiap alternatif disajikan pada tabel 14 .

Tabel 11. Nilai Alternatif dan Kriteria

\begin{tabular}{|l|r|r|r|r|r|r|r|}
\hline $\mathbf{A} / \mathbf{K}$ & $\mathbf{K}_{\mathbf{1}}$ & $\mathbf{K}_{\mathbf{2}}$ & $\mathbf{K}_{\mathbf{3}}$ & $\mathbf{K}_{\mathbf{4}}$ & $\mathbf{K}_{\mathbf{5}}$ & $\mathbf{K}_{\mathbf{6}}$ & $\mathbf{K}_{\mathbf{7}}$ \\
\hline $\mathbf{A}_{\mathbf{1}}$ & 3 & 5 & 4 & 5 & 4 & 6 & 6 \\
\hline $\mathbf{A}_{\mathbf{2}}$ & 3 & 5 & 5 & 4 & 3 & 5 & 6 \\
\hline $\mathbf{A}_{\mathbf{3}}$ & 4 & 4 & 3 & 3 & 2 & 5 & 4 \\
\hline $\mathbf{A}_{\mathbf{4}}$ & 5 & 3 & 3 & 2 & 3 & 4 & 3 \\
\hline
\end{tabular}

Tabel 12. Normalisasi Matrik

\begin{tabular}{|l|l|l|l|l|l|l|l|}
\hline $\mathbf{A} / \mathbf{K}$ & $\mathbf{K}_{\mathbf{1}}$ & $\mathbf{K}_{\mathbf{2}}$ & $\mathbf{K}_{\mathbf{3}}$ & $\mathbf{K}_{\mathbf{4}}$ & $\mathbf{K}_{\mathbf{5}}$ & $\mathbf{K}_{\mathbf{6}}$ & $\mathbf{K}_{\mathbf{7}}$ \\
\hline $\mathbf{A}_{\mathbf{1}}$ & 100 & $\begin{array}{l}166, \\
7\end{array}$ & $\begin{array}{l}133, \\
3\end{array}$ & 250 & 200 & 150 & 50 \\
\hline $\mathbf{A}_{\mathbf{2}}$ & 100 & $\begin{array}{l}166, \\
7\end{array}$ & $\begin{array}{l}166, \\
7\end{array}$ & 200 & 150 & 125 & 50 \\
\hline
\end{tabular}




\begin{tabular}{|l|l|l|l|l|l|l|l|}
\hline $\mathbf{A}_{3}$ & $\begin{array}{l}133, \\
3\end{array}$ & $\begin{array}{l}133, \\
3\end{array}$ & 100 & 150 & 100 & 125 & 75 \\
\hline $\mathbf{A} 4$ & $\begin{array}{l}166, \\
7\end{array}$ & 100 & 100 & 100 & 150 & 100 & 100 \\
\hline
\end{tabular}

Tabel 13. Bobot kali Matrik Ternormalisasi

\begin{tabular}{|r|l|l|l|l|l|c|c|}
\hline $\mathbf{A} / \mathbf{C}$ & $\mathbf{K}_{\mathbf{1}}$ & $\mathbf{K}_{\mathbf{2}}$ & $\mathbf{K}_{\mathbf{3}}$ & $\mathbf{K}_{\mathbf{4}}$ & $\mathbf{K}_{\mathbf{5}}$ & $\mathbf{K}_{\mathbf{6}}$ & $\mathbf{K}_{\mathbf{7}}$ \\
\hline $\mathbf{A}_{\mathbf{1}}$ & 37 & 38 & 20,8 & 27,3 & 14,6 & 6,6 & 1 \\
\hline $\mathbf{A}_{\mathbf{2}}$ & 37 & 38 & 26 & 21,8 & 11 & 5,5 & 1 \\
\hline $\mathbf{A}_{\mathbf{3}}$ & 49,3 & 30 & 15,6 & 16,4 & 7,3 & 5,5 & 1,5 \\
\hline $\mathbf{A}_{\mathbf{4}}$ & 61,7 & 23 & 15,6 & 10,9 & 11 & 4,4 & 2 \\
\hline
\end{tabular}

Tabel 14. Normalisasi Matrik

\begin{tabular}{|l|l|l|l|}
\hline No & Alternatif & Nilai Perhitungan & Rangking \\
\hline $\mathbf{1}$ & $\mathrm{A}_{1}$ & 145,25 & 1 \\
\hline $\mathbf{2}$ & $\mathrm{A}_{2}$ & 140,25 & 2 \\
\hline $\mathbf{3}$ & $\mathrm{A}_{3}$ & 126 & 4 \\
\hline $\mathbf{4}$ & $\mathrm{A}_{4}$ & 128,3 & 3 \\
\hline
\end{tabular}

Pada tabel 14 dapat dilihat bahwa A1 yaitu memiliki nilai tertinggi dengan nilai $=$ 145,25 dan nilai terkecil adalah A3 yaitu dengan nilai 126 .

\section{KESIMPULAN}

Dari empat alternatif yang dihitung, alternatif pertama yaitu Aqila Raina memiliki rengking tertinggi dengan nilai 145,25 dikuti oleh Diana dengan nilai 140,25 , selanjutnya Slamet Riadi dengan nilai 128,3 dan rengking terahir adalah Fatihul Abror dengan nilai 126. Dapat disimpulkan bahwa metode Composite Perfomence Index (CPI) yang dikombinasikan dengan metode Rank Order Centroid (ROC) dalam system pembobotan setiap kriteria dapat melakukan perengkingan yang baik dan mampu meminimalisir subjektifitas dari system pembobotan secara manual.

\section{DAFTAR PUSTAKA}

[1] B. Santoso and Armanto, "Penerapan Metode Composite Performance Index ( CPI ) Dalam Proses Penentuan Penerima Bantuan Program Bedah
Rumah Bagi Keluarga Miskin Dikota Lubuklinggau," J. Ilm. BETRIK, no. 02, pp. 74-82, 2020.

[2] B. Sudrajat, "Pemilihan Pengurus Organisasi Siswa Intra Sekolah Dengan Menggunakan Metode Composite Performa Index," J. Inov. Inform., vol. IV, no. 1, pp. 1-6, 2019.

[3] N. S. Tanjung, P. Dani Adelina, M. K. Siahaan, E. Purba, and J. Afriany, "Sistem Pendukung Keputusan Pemilihan Guru Teladan Dengan Menggunakan Metode Composite Perfomance Index (CPI)," J. Ris. Komput., vol. 5, no. 1, pp. 13-18, 2018, [Online]. Available: http://ejurnal.stmikbudidarma.ac.id/index.php/jurikom $\% 7$ C.

[4] P. D. Adelina, F. T. Waruwu, G. L. Ginting, and M. Sianturi, "Sistem Pendukung Keputusan Seleksi Penerimaan Koki Menerapkan Metode Composite Performance Index," KOMIK (Konferensi Nas. Teknol. Inf. dan Komputer), vol. 2, no. 1, pp. 6572, 2018, doi: 10.30865/komik.v2i1.909.

[5] R. Taufiq and A. A. Permana, "Sistem Pendukung Keputusan Penerimaan Karyawan Menggunakan Simple Additive Weighting Studi Kasus PT. Trafoindo Prima Perkasa," J. AlAZHAR Indones. SERI SAINS DAN Teknol., vol. 4, no. 4, p. 186, 2018, doi: 10.36722/sst.v4i4.309.

[6] Setianingsih, "SISTEM PENDUKUNG KEPUTUSAN REKRUTMEN KARYAWAN DENGAN MENGGUNAKAN METODE SAW DAN TOPSIS BERBASIS WEB (Studi Kasus di PT Intidaya Rajawali Mulia )," EBISNIS, vol. 1, no. 1, pp. 1-7, 2017, [Online]. Available: https://journal.stekom.ac.id/index.php/ pixel/article/download/68/64.

[7] R. Ariefianto and M. A. Irwansyah, "Sistem Pendukung Keputusan Seleksi Penerimaan Karyawan Baru 
Menggunakan Metode Analytical Hierarchy Proscess (Studi Kasus: PT. Infomedia Solusi Humanika (Insani) Kalimantan Barat)," J. Tek., 2015.

[8] I Made Arya Budhi Saputra, "Penentuan Lokasi Stup Menggunakan Pembobotan Rank Order Centroid (ROC) dan Simple Additive Weighting $(S A W), "$ J. Sist. dan Inform., vol. 15, no. 1, pp. 48-53, 2020, doi: 10.30864/jsi.v15i1.340.

[9] S. Silvilestari, "Penerapan Kombinasi Metode Simple Additive Weighting (SAW) dan Rank Order Centroid (ROC) dalam Keputusan Pemberian Kredit," J. Media Inform. Budidarma, vol. 3, no. 4, p. 371, 2019, doi: 10.30865/mib.v3i4.1509.

[10]M. Badaruddin, "Sistem Pendukung Keputusan Penilaian Kinerja Karyawan Menerapkan Kombinasi Metode Simple Additive Weighting (SAW) dengan Rank Order Centroid (ROC)," J. Media Inform. Budidarma, vol. 3, no. 4, p. 366, 2019, doi: 10.30865/mib.v3i4.1508.

[11]A. A. Tri Susilo, "Penerapan Metode Composite Performance Index (CPI) Pada Pemilihan Hotel Di Kota Lubuklinggau," J. RESTI (Rekayasa Sist. dan Teknol. Informasi), vol. 1, no. 3, pp. 204-2010, 2017, doi: 10.29207/resti.v1i3.79.

[12]S. S. Sundari and Y. F. Taufik, "Pegawai Baru Dengan Menggunakan Metode Simple Additive Weighting ( Saw)," Sisfotenika, vol. Vol. 4, No, pp. 140-151, 2014

[13] KARLITASARI, Lita, et al. Comparison of simple additive weighting (SAW) and composite performance index (CPI) methods in employee remuneration determination. In: IOP Conference Series: Materials Science and Engineering. IOP Publishing, 2017. p. 012020 . 